\title{
The Structure and Content of the Model of Pedagogical Conditions Binary Approach to Optimization of Control and Diagnostic Functions in Teaching "General pedagogy" to Students
}

\author{
Nadezhda Viktorovna Telegina ${ }^{1}$, Elvira Gabdelbarovna Galimova ${ }^{1} \&$ Alfiya Rafisovna Masalimova ${ }^{1}$ \\ ${ }^{1}$ Kazan (Volga region) Federal University, Russia \\ Correspondence: Nadezhda V. Telegina, Kazan (Volga region) Federal University, Kremlyovskaya Street, 18, \\ 420008, Kazan, Russia. E-mail: alfkazan@mail.ru
}

Received: September 23, 2014 Accepted: November 17, 2014 Online Published: December 2, 2014

doi:10.5539/ass.v11n1p364

URL: http://dx.doi.org/10.5539/ass.v11n1p364

\begin{abstract}
Some significant drawbacks of control and diagnostic functions in the sphere of higher professional education is associated with the absence of a binary approach to its implementation, which leads to the low significance level of education, personal motivation and responsibility of students for their academic activities and its results. The article is aimed to develop a model of pedagogical conditions of a binary approach to optimize control and diagnostic functions in teaching "General pedagogy" to students. A leading approach in the development of this model is binary approach, different from traditional and offering a fundamentally new strategy for solving problems of guaranteed quality of education. The article considers the structure and content of a pedagogical condition a binary approach model to optimization of control and diagnostic functions in teaching "General pedagogy" for students. The materials of this article have a practical importance in development and use of a test control system and self-control of students ' knowledge using ICT, as well as packets of control and diagnostic tasks and assignments for students studying "General pedagogy".
\end{abstract}

Keywords: control-diagnostic function, structure and content of the model, pedagogical conditions, binary approach, learning process

\section{Introduction}

One of the urgent tasks of developing modern professional education system is improving the control and diagnostic functions of training and modernization the system of assessment of vocational teacher education quality, which requires large-scale changes, including searching of new approaches for a building effective optimization of control models and diagnostic functions in the system of higher education (Andreev, 2010; Mikhaylishina \& Kurashkin, 2010). The binary approach to the optimization of the control and diagnostic functions in teaching "General pedagogy" for students is a set of General principles definition of goals, criteria, diagnostic tools, technologies and organizational structure of the process of assessing the quality of educational outcomes based on a combination of diagnostics and self-testing, control and self-control of planned learning outcomes (Serikov, 2008; Telegina et al., 2010).

The binary approach to the optimization of the control and diagnostic functions in the training essentially is a conceptual strategy that is different from mainstream of traditional education and offering a fundamentally new model for solving problems of quality education, including analysis of objective and subjective reasons of available indicators and criteria of quality education; pedagogical strategy of guaranteeing the quality of education in the framework of the Federal state educational standards of Higher professional education and professional standards; different from traditional models understanding relations between the subjects of education, that is, teachers and students, and their role in assessing the quality of the planned and achieved learning outcomes (Yalalov, 2012).

\section{Results and Discussions}

When developing the model, we relied on the fact that the binary approach is a holistic approach for improving teaching and learning, optimization objectives, criteria, diagnostic tools, technology of the optimization process of quality assessment, training, optimization of diagnostics (self-test), control (self-control), the planned and achieved learning outcomes (Hatsrinova, 2013; Ryabova, 2010; Rean et al., 2004; Andreev, 2005; Andreeva, 
2012). The binary approach to the optimization of control and diagnostic functions in the training essentially is a conceptual framework that is different from mainstream traditional education and offering a new model for solving problems of a guaranteed quality education, including analysis of objective and subjective reasons, the available indicators of the quality of education (Serikova, 2012; Anthony et al., 2003; Novikov, 2010; Heckhausen, 2008); pedagogical strategy of guaranteeing the quality of education in the framework of the Federal state educational standards of higher professional education (FGOS VPO) and professional standards; non-traditional models of understanding relations between the subjects of education and their role in assessing the quality of the planned and achieved learning outcomes.

Developed in the research process model of pedagogical conditions of a binary approach to optimization of control and diagnostic functions in teaching "General pedagogy" for students is a structural system effective implementation of a control and diagnostic functions within the binary approach in higher professional education (Figure 1).

The target model component is aimed to improve the effectiveness of teaching "General pedagogy" for students.

Indicators of the achievement of objectives are evaluation criteria in intended learning outcomes, i.e. the formation of the students in the learning process "of the General pedagogy competencies defined by contents of FGOS VPO.

The lessons of General pedagogy course was conducted on the historical, philological, mechanics and mathematics faculty of the Kazan State University, and then Kazan Federal University. To determine the pedagogical conditions of the binary approach to the optimization of the control and diagnostic functions, we relied on the approved program of "Pedagogy" discipline, where development of competencies during the course plays an important role. As an example, consider the competence of a student, formed in the result of mastering the discipline, the discipline of Pedagogy, prepared in accordance with the Federal State educational standard of higher professional education in the field of training 032700 Philology (qualification (degree) "bachelor"):

- willingness to cooperate with colleagues, ability to work in a team, ability to lead and to obey;

- understanding of a need for a continuous learning process, skills of independent work for further professional development and self-improvement, the pursuit of self-development, skills development and skills;

- $\quad$ awareness of the social importance of their profession, high motivation to professional activity;

- ability of organization independent professional labor process; skills to work in professional teams; the ability to provide these groups with appropriate materials in all kinds of professional activity.

Also an important component in the development of pedagogical conditions of a binary approach to optimization of control and diagnostic functions in the teaching of students are the requirements to mastering of the course.

Upon completion of the course students should

\section{know:}

- the history of development of scientific pedagogy and about leading trends and approaches in the examination of pedagogical phenomena taking place in the present;

- $\quad$ the system of pedagogical theories, learning patterns;

- the history of pedagogical ideas;

- the modern concept of development of General secondary and professional education;

\section{be able to:}

- $\quad$ analyze the educational situation;

- design decision of model pedagogical tasks.

- $\quad$ prepare and conduct training sessions and educational work;

- disseminate and popularize specialized knowledge;

\section{to own:}

- the main pedagogical concepts and categories;

- $\quad$ the system of pedagogical knowledge, on the basis of value attitude to teaching;

- to form a basic pedagogical skills: analytical, diagnostic, prognostic, engineering, design and organizational, assessment, communication and reflexive.

- develop important professional and personal qualities: empathy, tolerance, reflection and others. 


\section{Purpose:}

Improving the effectiveness of teaching "General pedagogy" for students

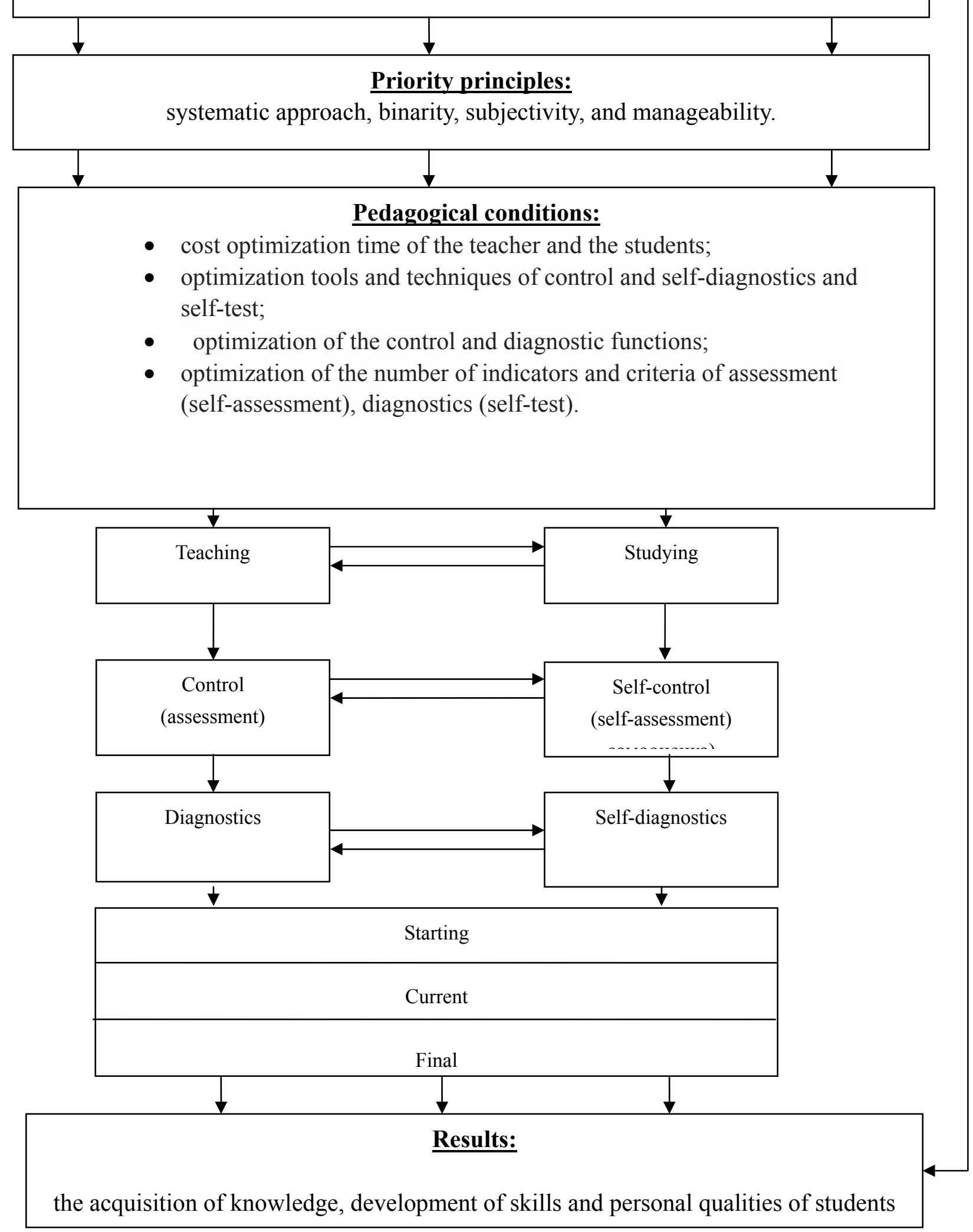

Figure 1. Model of pedagogical conditions of a binary approach to optimization of control and diagnostic functions in teaching "General pedagogy" for students 
Later in the model structure represents the priority principles for the implementation of a binary approach to optimization of control and diagnostic functions: system binary, subjectivity, and manageability. These principles define the priority of organizational and methodical build conditions and the implementation of the model.

For efficiency, the quality of higher education and achieve high academic results of the students identified the following pedagogical conditions of the binary approach, which include:

- the stimulation and motivation of teachers and students interest to the process and results of self-control, diagnostics and self- diagnostic;

- the optimization time for implementation of control and diagnostic functions, which is $3-5 \%$ of the total learning time;

- the optimal number of control points, which must be for a term ranging from 3 to 5 ;

- the optimal number of the applicability of the diagnostic assessment and diagnosis must be for a term ranging from 5 to 7 ;

- the most optimal and self-evaluation General pedagogical competence should be extended during the semester and submit a "cumulative" system matrix type;

- the efficiency of the binary approach in the implementation of control and diagnostic functions increases substantially with clear reasoning and deep understanding by students of the basic criteria of assessment of knowledge (depth, consistency, transfer to new conditions and competencies, taking into account the context and content of the diagnostic tasks and assignments;

- the binary approach to the optimization of the control and diagnostic functions in the training of students contributes to the formation of an active subject position of students, encourages reflective thinking in educational activities, promotes the acquisition of competencies self-assessment and self-diagnostics, which allows students more deeply and fully to know themselves, their strengths and weaknesses.

The following models are defined binary teaching methods, which require the consideration of dual methods of teaching and learning, as well as binary control methods that also involve consideration of the respective pairs of methods "control-self-control", "diagnostics - self test". Each situation is under the control of the quality of education in the discipline, aimed at identifying the dynamics of the level of knowledge, competencies, development of professional and personal qualities, in accordance with the model is accompanied in parallel by the actions of the student, aimed at self-control.

All these components are implemented on three levels: starter, current, final.

The structure, content model of pedagogical conditions of a binary approach to optimization of control and diagnostic functions in students "General pedagogy" and the indicators required quality of knowledge forms the teacher based on the requirements of the state educational standards, he is a control element that regulates self-government educational and diagnostic control functions of education.

\section{Conclusion}

The essence of a binary approach for optimization of pedagogical conditions of control and self-control of students ' knowledge using ICT is to define and organize objectives, structure and content of interrelated and interdependent processes of diagnostics and self-test, control and self-control of both process and outcomes. The structure of this process includes the content and model of the designed knowledge on the studied discipline, and the output has the quality of education, which is formed by the teacher in the minds of students achieved in the process of teaching and learning, the level of which is determined during diagnostics (self-test) and control (self-control).

The model of pedagogical conditions of use binary approach to the optimization of the control and diagnostic functions in teaching "General pedagogy" for students allows you to make the process and outcome of learning more effective and to some extent determines the feasibility of establishing a system of guaranteed quality of professional education on the basis of the binary approach.

\section{References}

Andreev, V. I. (2010). Conceptual teaching prognostics (p. 220). Kazan: Center for Information Technology.

Andreev, A. (2005). Knowledge or competence? Higher Education in Russia, 6, 3-11.

Andreeva, Y. V. (2012). Self-development as personal growth in the context of psycho-pedagogical strategies. 
Education and self-development, 6(34), 3-9.

Anthony, E., Larry, R. J., \& Ronald S. R. (2003). Understanding Human Motivation (p. 336). Blackwell Publishers.

Hatsrinova, O. J. (2013). Methods of assessing pedagogical competence Masters. Education and self-development, 1(35), 83-86.

Heckhausen, J. (2008). Motivation and action (p. 528). Cambridge University Press.

Mikhaylishina, G. F., \& Kurashkin, A. A. (2010). Modern monitoring in education: principles of classification. Education and self-development, 6(22), 78-83.

Novikov, A. M. (2010). Grounds pedagogy: A manual for teachers and textbook authors (p. 28). Moscow. Egves Press.

Rean, A., Bordovskaya, N., \& Rozum, S. (2004). Psychology and Pedagogy (p. 432). Saint Petersburg, Peter Press.

Ryabova, T. V. (2010). The evaluation scale features of the system decision. Education and self-development, 3(19), 145-150.

Serikov, V. V. (2008). Education as a kind of educational activity: Studies (p. 256). Moscow: Academy Press.

Serikova, V. V. (2012). Personality development in the educational process (p. 448). Moscow. Logos Press.

Telegina, N. V., Andreev, V. I., \& Golovanov, I. I. (2010). Tests assess knowledge and skills in the course "Pedagogy" (p. 36). Kazan. Center for Innovative Technologya.

Yalalov, F. G. (2012). Multidimensional pedagogical competence. Pedagogy, 4, 45-53.

\section{Copyrights}

Copyright for this article is retained by the author(s), with first publication rights granted to the journal.

This is an open-access article distributed under the terms and conditions of the Creative Commons Attribution license (http://creativecommons.org/licenses/by/3.0/). 